\title{
HLA DR antigens and disease expression in rheumatoid arthritis
}

\author{
A. J. GRIFFin, P. WOOLEY, G. S. PANAYI, AND J. R. BATCHELOR*
}

From the Departments of Rheumatology and Medicine, Guy's Hospital, St Thomas Street, London SE1 9RT, and the * Department of Immunology, Royal Postgraduate Medical School, Hammersmith Hospital, London W12

SUMMARY Ninety-four patients with rheumatoid arthritis who possessed one or more of the HLA DR alloantigens 2, 3, or 4 were studied to investigate the genetic influence on disease severity and prognosis. In those with a disease duration of less than 10 years radiological damage was less in patients with DR2 than in those without this antigen. When current joint scores were compared, patients with this antigen had less evidence of disease than patients with DR3 or 4, DR3 patients having the highest scores. The presence of nodules and Sjögren's syndrome were less common in the DR2 patients. Variability in response to disease modifying drugs according to the patient's HLA DR antigen status may explain these differences. It is concluded, however, that possession of HLA DR2 may be an indicator of good prognosis in patients with rheumatoid arthritis.

It is now well known that rheumatoid arthritis (RA) is strongly associated with HLA DR $4,{ }^{1-3}$ though a recent study suggested that this may be so only in the seropositive group. ${ }^{4}$ Whether the severity of disease is also under genetic control is still unresolved. Thus high titres of IgM rheumatoid factor and the presence of nodules, features conventionally associated with poor prognosis, have been shown to be associated with DR $3{ }^{3}$ while it has been suggested that DR4 may be a genetic marker predisposing to the production of IgM rhe umatoid factor. ${ }^{4}$

We decided therefore to investigate the role of DR2, 3, and 4 in other clinical manifestations of RA with special reference to radiological and clinical joint involvement and response to treatment with sodium aurothiomalate (SAT) or D-penicillamine (DP). DR2 was included in the study because the prevalence of this antigen has been shown to be significantly lower in patients with RA than in controls. ${ }^{35}$

\section{Patients and methods}

Patients. Ninety-four patients with classical or definite $\mathrm{RA}^{6}$ who were attending the Rheumatology Outpatient Clinic were chosen for the study. Of these, 65 had received either sodium aurothiomalate

Accepted for publication 16 March 1983.

Correspondence to Professor G. S. Panayi. or D-penicillamine for a minimum of 9 months. Thirty-nine were female and 26 male, with a disease duration of 1-38 years. The other 29 patients represented a similar group of rhaumatoid patients who had had gold for less than this period and had to be excluded in comparison of past and present joint scores. There were 19 females and 10 males with disease duration of 1-20 years. Patients were started on second-line drug treatment because of active and progressive disease who had failed conventional therapy of nonsteroidal drugs, local steroid injections, and physiotherapy. The age of onset was calculated for all patients and the presence of nodules noted.

Radiological joint damage. $X$-ray scores of the hands and feet within the previous 3 months were calculated according to the manner described by Sharp et al. ${ }^{7}$ Patients were divided into 2 groups with disease duration of greater or less than 10 years and further divided into groups of erosive scores of greater or less than 10 .

Keratoconjunctivitis sicca. A Schirmer's test was performed on the group of 65 patients who had been on long-term gold or penicillamine, and patients with a positive or borderline result had an ophthalmological examination including a repeat Schirmer's test, rose Bengal stain, and an examination under a slitlamp to conform or exclude the presence of keratoconjunctivitis sicca.

Past joint involvement. A score was obtained of 
past joint involvement in the 65 patients by asking patients which joints had been involved at any stage in their history, and this was confirmed by reference to the notes where possible. A total of 47 joints could have been involved, the metacarpophalangeal joints, proximal interphalangeal joints, and metatarsophalangeal joints being scored separately, and the sternoclavicular and talocalcaneal joints being excluded. Other joints scored were the cervical spine (1), temporomandibular joints (2), shoulders (2), elbows (2), wrists (2), hips (2), knees (2), ankles (2), midtarsal (2).

Present joint involvement. Present joint scores were obtained by examining the patient and carrying out a conventional Ritchie index. ${ }^{8}$

Tissue typing. Patients were tissue typed as described previously by us. ${ }^{39}$

Assessment of results. All numbers or scores involved were noted in 3 groups for each antigen in an effort to exclude influences of mixed antigens in any differences found. For example, comparisons could be made between patients possessing DR 4 with all those without this antigen and with all those with DR4 but not DR2 or 3. Furthermore, some tests were performed on all 94 patients and others in only 65 , and consequently results are presented as appropriate.

\section{Results}

Distribution of HLA antigens. The distribution of the antigens HLA DR2, 3, or 4 (Table 1) cannot be compared with that in a healthy control group because we have excluded all patients typed without these antigens, but the distribution of antigens was similar to that in a previous study by us. ${ }^{3}$ Only 9 patients were common to both studies.

Onset of disease. Disease onset was latest (50 yr, SD $12 \cdot 5$, range 28 to 75 years) in patients with DR4 without DR2 or DR3 and earliest in those with DR2 alone or in combination with DR3 or DR4 (42.9, SD $10 \cdot 2$, range 25 to 66 years). The differences were not significant (data not shown).
Extra-articular features. Nodules were present in 31 out of 94 patients, $74.2 \%$ possessing DR4 (prevalence $70 \cdot 2 \%$ ), $34.5 \%$ possessing DR3 (prevalence $30 \cdot 1 \%$ ), and only $9.7 \%$ possessing DR2 (prevalence $22 \cdot 3 \%$ ), a marked reduction in the latter group (Table 2). If single DR antigen groups were examined, the findings were the same, only one patient out of 8 with DR2 antigen having nodules.

There was a similar discrepancy in the presence of Sjögren's syndrome, which was present in 31 out of 65 patients tested. Only 4 patients with DR2 out of a total of 16 were affected, half the expected frequency $\left(\chi^{2}=4 \cdot 0, p<0 \cdot 05\right)($ Table 3$)$.

Radiological joint involvement. The $x$-ray scores were divided into groups above or below 10 years of disease duration and more or less than 10 erosions in order to obtain some conformity within the groups.

Table 2 The presence of nodules in 94 patients with rheumatoid arthritis possessing the alloantigens DR4, DR3, or DR2.

\begin{tabular}{lllc}
\hline $\begin{array}{l}\text { HLA DR } \\
\text { antigen }\end{array}$ & $\begin{array}{l}\text { Number of } \\
\text { patients }\end{array}$ & \multicolumn{2}{l}{ Patients with nodules } \\
\cline { 2 - 4 } & & Seen & Expected \\
\hline DR4 & 66 & 23 & 22 \\
DR3 & 29 & 10 & 9 \\
DR2 & 21 & $3^{*}$ & 7 \\
\hline
\end{tabular}

${ }^{*} \chi^{2}=4 \cdot 6, p<0 \cdot 05$.

Table 3 The presence of Sjögren's syndrome in 65 patients with rheumatoid arthritis possessing the alloantigens DR4, $D R 3$, or $D R 2$

\begin{tabular}{llcc}
\hline $\begin{array}{l}\text { HLA DR } \\
\text { antigen }\end{array}$ & $\begin{array}{l}\text { Number of } \\
\text { patients }\end{array}$ & \multicolumn{2}{l}{ Patients with Sjögren's syndrome } \\
\cline { 3 - 4 } & & Seen & Expected \\
\hline DR4 & 44 & 20 & 21 \\
DR3 & 23 & 8 & 11 \\
DR2 & 16 & $4^{*}$ & 8 \\
\hline
\end{tabular}

${ }^{*} \chi^{2}=4 \cdot 0, p<0 \cdot 05$

Table 1 The distribution of HLA DR2, 3, or 4 antigens singly or in combination in the 94 patients with rheumatoid arthritis. The number (percentage) of patients in each group is shown. In this and all subsequent Tables the 'expected' number of patients with a particular manifestation has been calculated from the percentage distribution in all 94 patients studied.

HLA DR antigens

\begin{tabular}{|c|c|c|c|c|c|c|c|c|}
\hline \multicolumn{3}{|l|}{$D R 4$} & \multicolumn{3}{|l|}{$D R 3$} & \multicolumn{3}{|l|}{$D R 2$} \\
\hline $\begin{array}{l}\text { DR4 } \\
\text { positive }\end{array}$ & $\begin{array}{l}\text { DR4 } \\
\text { negative }\end{array}$ & $\begin{array}{l}\text { DR4 positive } \\
\text { without } D R 2 / \\
\text { DR3 }\end{array}$ & $\begin{array}{l}\text { DR3 } \\
\text { positive }\end{array}$ & $\begin{array}{l}\text { DR3 } \\
\text { negative }\end{array}$ & $\begin{array}{l}\text { DR3 positive } \\
\text { without } D R 4 \text { | } \\
\text { DR2 }\end{array}$ & $\begin{array}{l}\text { DR2 } \\
\text { positive }\end{array}$ & $\begin{array}{l}\text { DR2 } \\
\text { negative }\end{array}$ & $\begin{array}{l}\text { DR2 positive } \\
\text { without } D R 41 \\
D R 3\end{array}$ \\
\hline $\begin{array}{l}66 \\
(70 \cdot 2)\end{array}$ & $\begin{array}{l}28 \\
(29 \cdot 8)\end{array}$ & $\begin{array}{l}48 \\
(51 \cdot 0)\end{array}$ & $\begin{array}{l}29 \\
(30 \cdot 1)\end{array}$ & $\begin{array}{l}65 \\
(69 \cdot 0)\end{array}$ & $\begin{array}{l}16 \\
(17 \cdot 0)\end{array}$ & $\begin{array}{l}21 \\
(22 \cdot 3)\end{array}$ & $\begin{array}{l}73 \\
(77 \cdot 7)\end{array}$ & $\begin{array}{l}8 \\
(8 \cdot 5)\end{array}$ \\
\hline
\end{tabular}


There were only 3 patients out of 32 with a disease duration of greater than 10 years and a score of less than 10 , and all were erosive (Table 4 ). All 3 were DR4-positive and one was DR2,4-positive. However, there is a significant lack of patients in the DR2-positive group with a disease duration of less than 10 years and an erosive score of greater than 10 $(p<0.025)$ and a nonsignificant excess in those with a score of less than 10 (Table 5).

Table $4 X$-ray scores in 32 patients with rheumatoid arthritis possessing the alloantigens $D R 4, D R 3$, or $D R 2$ and a disease duration of more than 10 years. The differences are not significant

\begin{tabular}{|c|c|c|c|c|}
\hline \multirow{2}{*}{$\begin{array}{l}\text { HLA DR } \\
\text { antigen }\end{array}$} & \multicolumn{2}{|c|}{$X$-ray score $<10 n=3$} & \multicolumn{2}{|c|}{$X$-ray score $>10 n=29$} \\
\hline & $\begin{array}{l}\text { No. of } \\
\text { patients }\end{array}$ & $\begin{array}{l}\text { Expected } \\
\text { no. }\end{array}$ & $\begin{array}{l}\text { No. of } \\
\text { patients }\end{array}$ & $\begin{array}{l}\text { Expected } \\
\text { no. }\end{array}$ \\
\hline DR4 & 3 & 2 & 10 & 20 \\
\hline DR3 & 0 & 1 & 11 & 9 \\
\hline DR2 & 1 & 1 & 9 & 7 \\
\hline
\end{tabular}

Table $5 X$-ray scores in 62 patients with rheumatoid arthritis possessing the alloantigens $D R 4, D R 3$, or DR2 and a disease duration of less than 10 years.

\begin{tabular}{|c|c|c|c|c|}
\hline \multirow{2}{*}{$\begin{array}{l}H L A D R \\
\text { antigen }\end{array}$} & \multicolumn{2}{|c|}{$X$-ray score $<10 n=26$} & \multicolumn{2}{|c|}{$X$-ray score $>10 n=36$} \\
\hline & $\begin{array}{l}\text { No. of } \\
\text { patients }\end{array}$ & $\begin{array}{l}\text { Expected } \\
\text { no. }\end{array}$ & $\begin{array}{l}\text { No. of } \\
\text { patients }\end{array}$ & $\begin{array}{l}\text { Expected } \\
\text { no. }\end{array}$ \\
\hline DR4 & 16 & 18 & 28 & 25 \\
\hline DR3 & 8 & 8 & 10 & 11 \\
\hline DR2 & 8 & 6 & $3^{*}$ & 8 \\
\hline
\end{tabular}

${ }^{*} \chi^{2}=5 \cdot 77, p<0 \cdot 025$.
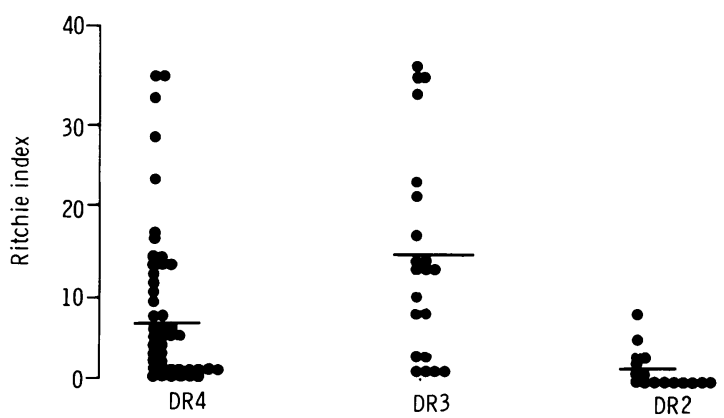

Fig 1 Present active joint score (Richie index) in 65 patients with rheumatoid arthritis possessing the alloantigens DR4, $D R 3$, or $D R 2$ and treated with sodium aurothiomalate or $D$-penicillamine for at least 9 months. Ritchie index for the different groups (mean +SEM): DR4 7.9 $\pm 9.9, D R 313 \cdot 4$ $\pm 11 \cdot 6$, and DR2 $1 \cdot 6 \pm 2 \cdot 5)$.
Table 6 Joint scores in 65 patients with rheumatoid arthritis treated with sodium aurothiomalate or D-penicillamine for at least 9 months showing the effects of mixed or single alloantigens

\begin{tabular}{rlll}
\hline $\begin{array}{l}\text { Total } \\
\text { group }\end{array}$ & $\begin{array}{l}\text { Present joint } \\
\text { score-Ritchie } \\
\text { index }\end{array}$ & $\begin{array}{l}\text { Total past } \\
\text { joint score }\end{array}$ & $\begin{array}{l}\text { No. of } \\
\text { patients }\end{array}$ \\
\hline Total group & $\begin{array}{l}\text { Mean score }= \\
8 \pm 9 \cdot 8\end{array}$ & $\begin{array}{l}\text { Mean score }= \\
36 \pm 10 \cdot 6\end{array}$ & $n=65$ \\
DR4 (4,-) & $7 \pm 7 \cdot 9$ & $34 \pm 11 \cdot 2$ & 30 \\
$(4,3)$ & $20 \pm 9 \cdot 4$ & $45 \pm 2 \cdot 5$ & 7 \\
DR3 (3,-) & $13 \pm 11 \cdot 8$ & $39 \pm 6 \cdot 0$ & 12 \\
DR2 (2,-) & $1 \pm 1 \cdot 6$ & $28 \pm 11 \cdot 6$ & 5 \\
$(2,3)$ & $3 \pm 3 \cdot 3$ & $34 \pm 4 \cdot 8$ & 4 \\
$(2,4)$ & $2 \pm 2 \cdot 0$ & $20 \pm 11 \cdot 8$ & 7 \\
\hline
\end{tabular}

$\pm=$ Standard deviation.

Clinical joint involvement. The most interesting findings were those relating to present joint scores, as the DR2-positive group appeared to be markedly less active than the DR3 or DR4 groups, but reaching significance only against DR3 $(\mathrm{p}=<0 \cdot 025)$ (Fig. 1).

Though a past total joint score relies on memory, this showed a trend, being highest in the DR3 group, intermediate in the DR4 group, and lowest in the DR2 group (Table 6). The number of patients who had only DR2 or DR3 was very small, but less than one joint was involved on average in the DR2positive (DR3,DR4-negative) group compared with 13 in the DR3-positive (DR2,4-negative) group. The worst scores were present in the seven patients who possessed DR3 and DR4, their past score being 45 and present 20 (Table 6).

\section{Discussion}

Our results suggest that the presence of HLA DR2, which has a reduced prevalence in patients with rheumatoid arthritis, ${ }^{35}$ may be an indicator of less severe disease and of a better response to second-line drug therapy. The presence of nodules and Sjögren's syndrome was less common in this group, their present joint scores were markedly superior to the patient with HLA DR3 or 4, and radiographic destruction in the first 10 years of disease was also less severe. This latter result may reflect the present enthusiasm for treating patients with gold or penicillamine earlier in their disease, so that patients with a disease duration of greater than 10 years may not have had the benefit of them in time to slow their erosive damage. If a protective effect is present, this may not help beyond the first few years of the disease.

Scherak et al. ${ }^{10}$ attempted to compare the incidence of these 3 antigens with severe destruction on $x$-ray (Steinbrocker's stage III and IV) and found no 
significant difference, but he did not allow for disease duration differences and there were only 5 patients with DR2. We also attempted to find out whether any one antigen was dominant in its effect on disease severity, as most patients had combinations of DR2, 3 , or 4 antigens, but failed to do so because of the small number of patients with single HLA DR antigens. Criticisms can be made of the patient population we chose to study, which excluded those with nonerosive or mildly erosive seronegative rheumatoid arthritis, who may never be treated with gold or penicillamine, but we wished not only to accentuate differences by choosing the most active group of patients but to see whether drug response has any link with immunogenetic markers.

We feel that there is a suggestion that patients with HLA DR2 have a milder disease, better prognosis, and better response to gold or penicillamine. The results are of special interest because HLA DR2 has been shown to be a marker of resistance against type I diabetes ${ }^{11}$ and HLA DR2 may play a similar role in rheumatoid arthritis. ${ }^{35}$ Prospective clinical studies and studies of families with 2 or more affected members are now needed in order to confirm or refute the trends demonstrated in this paper.

We thank Dr R. Grahame and Dr T. Gibson for allowing us to study their patients and Mrs J. E. Dunn for her help in the statistical analyses. The work was financed by a project grant from the Arthritis and Rheumatism Council.

\section{References}

1 Batchelor J R, Morris P J. HLA and disease. In: Bodmer W F, Batchelor J R, Bodmer J G, Festenstein H, Morris P J, eds. Histocompatibility testing. Copenhagen: Munksgaard, 1977: 205-58.

2 Stastny P. Association of the B-cell alloantigen DRw4 with rheumatoid arthritis. $N$ Engl J Med 1978; 298: 869-71.

3 Panayi G S, Woolley P, Batchelor J R. Genetic basis of rheumatoid disease: HLA antigens, disease manifestations and toxic reactions to drugs. $\mathrm{Br}$ Med J 1978; ii: 1326-8.

4 Dobloug J H, Førre $\emptyset$, Kass E, Thorsby E. HLA antigens and rheumatoid arthritis. Association between HLA-DRw 4 positivity and IgM rheumatoid factor production. Arthritis Rheum 1980; 23: 309-13.

5 Thomsen M, Morling N, Snorrason E, et al. HLA Dw4 and rhe umatoid arthritis. Tissue Antigens 1979; 13: 56-60.

6 Ropes M W, Bennett G A, Cobb S, Jacox R, Fessar R. Diagnostic criteria for rheumatoid arthritis. Ann Rheum Dis 1958; 18: 49.

7 Sharp J T, Lidsky M D, Collins L C, Moreland J. Methods of scoring the progression of radiological changes in rheumatoid arthritis. Arthritis Rheum 1971; 14: 706-20.

8 Ritchie D M, Boyle J A, McInnes J M, et al. Clinical studies with an articular index for the assessment of joint tenderness in patients with rheumatoid arthritis. $Q \mathrm{~J}$ Med 1968; 37: 393-406.

9 Wooley P H, Griffin J, Panayi G S, Batchelor J R, Welsh K I, Gibson $T$ J. HLA-DR antigens and toxicity to sodium aurothiomalate and D-penicillamine in rheumatoid arthritis. $N$ Engl J Med 1980; 303: 300-2.

10 Scherak O, Smolen J S, Mayr W R. Rheumatoid arthritis and B lymphocyte alloantigen HLA DRw4. J Rheumatol 1980; 7: 9-12.

11 Ilonen J, Herva E, Tiilikainen A, Akerblom H K, Koivukangas T, Kouvalainen K. HLA-DW2 as a marker of resistance against juvenile diabetes mellitus. Tissue Antigens 1978; 11: 144-6. 